\title{
Seeing the Light: The Use of Zebrafish for Optogenetic Studies of the Heart
}

\author{
Jonathan S. Baillie ${ }^{1}$, Matthew R. Stoyek ${ }^{1}$ and T. Alexander Quinn ${ }^{1,2 *}$ \\ ${ }^{1}$ Department of Physiology and Biophysics, Dalhousie University, Halifax, NS, Canada, ${ }^{2}$ School of Biomedical Engineering, \\ Dalhousie University, Halifax, NS, Canada
}

Optogenetics, involving the optical measurement and manipulation of cellular activity with genetically encoded light-sensitive proteins ("reporters" and "actuators"), is a powerful experimental technique for probing (patho-)physiological function. Originally developed as a tool for neuroscience, it has now been utilized in cardiac research for over a decade, providing novel insight into the electrophysiology of the healthy and diseased heart. Among the pioneering cardiac applications of optogenetic actuators were studies in zebrafish, which first demonstrated their use for precise spatiotemporal control of cardiac activity. Zebrafish were also adopted early as an experimental model for the use of optogenetic reporters, including genetically encoded voltage- and calcium-sensitive indicators. Beyond optogenetic studies, zebrafish are becoming an

OPEN ACCESS

Edited by:

Stephan E. Lehnart,

University Medical Center

Göttingen, Germany

Reviewed by:

Alexandra Zahradnikova, Slovak Academy of Sciences, Slovakia

Claudia Richter,

Deutsches

Primatenzentrum, Germany

*Correspondence:

T. Alexander Quinn

alex.quinn@dal.ca

Specialty section:

This article was submitted to

Cardiac Electrophysiology,

a section of the journal

Frontiers in Physiology

Received: 28 July 2021

Accepted: 19 October 2021

Published: 23 December 2021

Citation:

Baillie JS, Stoyek MR and Quinn TA (2021) Seeing the Light: The Use of Zebrafish for Optogenetic Studies of the Heart. Front. Physiol. 12:748570.

doi: 10.3389/fphys.2021.748570 increasingly important tool for cardiac research, as they combine many of the advantages of integrative and reduced experimental models. The zebrafish has striking genetic and functional cardiac similarities to that of mammals, its genome is fully sequenced and can be modified using standard techniques, it has been used to recapitulate a variety of cardiac diseases, and it allows for high-throughput investigations. For optogenetic studies, zebrafish provide additional advantages, as the whole zebrafish heart can be visualized and interrogated in vivo in the transparent, externally developing embryo, and the relatively small adult heart allows for in situ cell-specific observation and control not possible in mammals. With the advent of increasingly sophisticated fluorescence imaging approaches and methods for spatially-resolved light stimulation in the heart, the zebrafish represents an experimental model with unrealized potential for cardiac optogenetic studies. In this review we summarize the use of zebrafish for optogenetic investigations in the heart, highlighting their specific advantages and limitations, and their potential for future cardiac research.

Keywords: cardiac electrophysiology, opsins, membrane potential, intracellular calcium, genetically encoded voltage indicators (GEVIs), genetically encoded calcium indicators (GECIs)

\section{OPTOGENETICS IN CARDIAC RESEARCH}

Optogenetics involves the measurement and manipulation of cellular activity using genetically encoded light-sensitive proteins (Deisseroth et al., 2006; Miesenböck, 2009). Originally developed as a set of tools for neuroscience to activate or silence neuronal circuits and observe neuronal activity (Li et al., 2005; Nagel et al., 2005), optogenetic "reporters" (for measurement of membrane potential (Siegel and Isacoff, 1997; Sakai et al., 2001; Ataka and Pieribone, 2002) or intracellular 
TABLE 1 | Advantages and limitations of the zebrafish for cardiac optogenetic studies.

\begin{tabular}{ll}
\hline Advantages & Limitations \\
\hline & \\
-Relatively low cost (time, effort, money) & -Genome duplication (24\% of genes \\
-Fully sequenced genome & have more than one ortholog) \\
-Relatively easy genetic manipulation & -Small, two-chambered heart \\
-Large number of available transgenic & -Relatively low-pressure system \\
lines & -Lack transverse tubules \\
-Majority of cardiac genes have human & -Limited release of calcium from \\
ortholog & sarcoplasmic reticulum following \\
-Externally developing, transparent & excitation \\
embryo & -Low sensitivity of ryanodine \\
-Amenable to high throughput studies & receptors to calcium \\
-Comparable heart rate, action potential & -Dependence of calcium transient on \\
morphologies, ion channels, and & sarcolemmal influx \\
calcium-handling proteins to human & \\
-Intra- and extracardiac regulatory & \\
pathways and mechanisms similar to & \\
human & \\
-Human cardiac diseases can & \\
be recapitulated & \\
\end{tabular}

calcium [Ca ${ }^{2+}$ ] (Miyawaki et al., 1997, 1999; Baird et al., 1999)) and 'actuators' [for modulation of membrane potential (Nagel et al., 2002, 2003; Boyden et al., 2005)] have now been utilized in cardiac research for over a decade (Entcheva and Kay, 2021). Cardiac optogenetics has had a wide-range of applications, including: (i) all-optical studies of cardiac electrophysiology and high-throughput drug screening; (ii) cell-specific measurement or control to investigate cardiac sub-populations (e.g., myocytes, Purkinje cells, fibroblasts, neurons, and immune cells); (iii) manipulation of cardiac ion channels, G protein- coupled receptor signaling, and energetics; (iv) control of action potential morphology or excitation waves; and (v) cardiac pacing, cardioversion/defibrillation, or arrhythmia termination/ablation. Some of the pioneering studies that applied optogenetics to the heart were performed in zebrafish (Danio rerio). Here we provide an overview of the use of zebrafish for cardiac optogenetic studies, highlighting their advantages, limitations, and future potential [for a more general consideration of cardiac optogenetics, please see the recent review by Entcheva and Kay (Entcheva and Kay, 2021)].

\section{USE OF ZEBRAFISH FOR OPTOGENETIC STUDIES OF THE HEART}

The zebrafish has become an important integrative animal model for cardiac research, based on its particular advantages as an experimental tool (Table 1) (Gut et al., 2017; Stoyek and Quinn, 2018). The zebrafish offers a fully sequenced genome, which can be easily altered using standard genetic techniques at relatively low cost (in terms of time, effort, and money) (Rafferty and Quinn, 2018; Stoyek et al., in press), and almost every cardiac gene has a human ortholog with analogous function (Howe et al., 2013). This high degree of genetic similarity has permitted researchers to recapitulate a variety of human cardiac diseases in the zebrafish (Bowley et al., in press), which can be studied in a high throughput manner (Kithcart and MacRae, 2018). Functionally, the zebrafish heart has comparable heart rate, action potential morphologies, ion channels (Ravens, 2018), and $\mathrm{Ca}^{2+}$-handling proteins (van Opbergen et al., 2018b) to human. Furthermore, it has been shown that cardiac regulatory pathways and mechanisms of both intracardiac (MacDonald et al., 2017) and extracardiac (Stoyek et al., 2016) origin are similar to human, and like the cardiac electrophysiology of the zebrafish (Nemtsas et al., 2010), are often more so than rodents.

Of course, as with any experimental model, there are also limitations to the zebrafish's use (Table 1). The zebrafish heart is small, has only two chambers (one atrium and one ventricle, rather than the four chambers found in human), and generates relatively low pressures ( $\mathrm{Hu}$ et al., 2001). While over $70 \%$ of human genes have at least one zebrafish ortholog, $24 \%$ of genes have more than one ortholog (due to a duplication of the zebrafish genome), which can confer redundancy in gene function and confound results of genetic manipulations (Howe et al., 2013). Functionally, while cardiac electrophysiology appears strikingly similar to humans (Vornanen and Hassinen, 2016; Ravens, 2018), there are important differences in cellular calcium cycling (Genge et al., 2016; van Opbergen et al., 2018b). Zebrafish cardiomyocytes have a lack of transverse tubules (Brette et al., 2008), and even though sarcoplasmic reticulum $\mathrm{Ca}^{2+}$ levels are much higher in the zebrafish, release of $\mathrm{Ca}^{2+}$ from the sarcoplasmic reticulum following excitation $\left(\mathrm{Ca}^{2+}\right.$ induced $\mathrm{Ca}^{2+}$ release) appears to be limited (due in part to a low sensitivity of ryanodine receptors to $\mathrm{Ca}^{2+}$ ) (Bovo et al., 2013). As a result, sarcolemmal $\mathrm{Ca}^{2+}$ influx is responsible for $\sim 80 \%$ of the $\mathrm{Ca}^{2+}$ transient in zebrafish cardiomyocytes (compared to $25 \%$ in human) (Bovo et al., 2013), although this remains somewhat controversial, as others have shown a strong dependence of contractile force on sarcoplasmic reticulum $\mathrm{Ca}^{2+}$ release (Haustein et al., 2015) and the existence of $\mathrm{Ca}^{2+}$ sparks with characteristics similar to mammals (Llach et al., 2011). Zebrafish also have a higher sodium- $\mathrm{Ca}^{2+}$ exchanger current than in mammals, such that its reverse-mode has been shown to trigger sarcoplasmic reticulum $\mathrm{Ca}^{2+}$ release (Zhang et al., 2011).

Considering its use specifically for cardiac optogenetic studies, the zebrafish has a further advantage over other animal models, in that the entire zebrafish heart can be optically accessed in vivo in the transparent, externally developing embryo (van Opbergen et al., 2018a) or in situ in the relatively small, isolated adult heart (Stoyek et al., 2018), in a manner not possible in mammals. While other non-mammalian models may have a similar advantage (e.g., Drosophila melanogaster [Wolf et al., 2006) and Xenopus laevis (Warkman and Krieg, 2007)], they are limited in other ways. For instance, while Drosophila have been highly utilized for studies of cardiac genetics (Wolf et al., 2006), it is an invertebrate, and differences in the morphology of its heartwhich is a tube-limits its applicability for functional studies (Rotstein and Paululat, 2016). The heart of Xenopus, on the other hand, is in some ways more anatomically similar to humans than zebrafish-for instance, it has a pulmonary circulation-but there is a limited genetic tool box for their transgenesis (Ishibashi et al., 2008). 
Ultimately, the similarities of zebrafish to human, and its particular experimental advantages, have resulted in it being a popular experimental model for optogenetic investigations, both for neuroscience [the brain and nervous system can also be optically accessed in the whole animal (Del Bene and Wyart, 2012; Simmich et al., 2012; Portugues et al., 2013)] and for cardiovascular research (Table 2), which is the focus of this review.

\section{STUDIES UTILIZING OPTOGENETIC REPORTERS IN THE ZEBRAFISH HEART}

The electrical activity of the heart has been optically monitored for decades, well before the emergence of modern optogenetics and the use of functional fluorescent proteins. In the 1970s, Salama and Morad published the first reports of the use of voltage sensitive fluorescent dyes to record cardiac action potentials (Salama and Morad, 1976; Morad and Salama, 1979). Since that time, optical mapping of membrane potential and intracellular $\mathrm{Ca}^{2+}$ in the whole heart or isolated tissue and cells has become a "standard" technique in many research labs (Herron et al., 2012; Jaimes et al., 2016; Berenfeld and Efimov, 2019), including studies using zebrafish (Sabeh et al., 2012; Lin et al., 2020). The use of optogenetic reporters (genetically encoded voltage and $\mathrm{Ca}^{2+}$ indicators, GEVIs and GECIs, respectively) have additional advantages as they allow for organ-, organelle-, and cell-specific measurements and for in vitro and in vivo longitudinal studies. There is now a wide array of GEVIs and GECIs available for use in the heart, with a range of excitation and emission spectra, light sensitivity and signal intensity, temporal dynamics, and other properties that dictate their specific use (Figure 1) (Kaestner et al., 2014, 2015; Koopman et al., 2017).

\section{Genetically Encoded $\mathrm{Ca}^{2+}$ Indicators (GECIs)}

The first use of an optogenetic reporter in the heart was described in the early 2000s. This involved GCaMP2, which includes a circularly permutated EGFP within an M13/Calmodulin fusion protein that fluoresces when it binds $\mathrm{Ca}^{2+}$, to record $\mathrm{Ca}^{2+}$ waves in the isolated mouse heart and in open chest animals (Tallini et al., 2006). This was followed by a study that used GCaMP2 to demonstrate successful engraftment and electrical coupling of embryonic cardiomyocytes with surrounding myocardium in the infarcted mouse heart (Roell et al., 2007). Around the same time, the potential for using zebrafish to image intracellular $\mathrm{Ca}^{2+}$ in the intact animal was also being realized. The first published report involved the use of a transgenic zebrafish line with cardiacspecific expression of gGCaMP driven by the cardiac myosin light chain $2(\mathrm{cmlc} 2)$ gene promoter $\left(\mathrm{Tg}(\mathrm{cmlc2} \text { : } g \mathrm{CaMP})^{s 878}\right)$. It was used to investigate a transgenic zebrafish model of inherited long QT syndrome in which a loss of rapid delayed-rectifier potassium current $\left(I_{\mathrm{Kr}}\right)$ due to a mutation in the $s 290$ allele of the $k c n h 2$ gene $\left(k c n h 2^{s 290}\right)$ results in mechanical ventricular asystole (Arnaout et al., 2007). Using selective plane illumination microscopy (SPIM) and excitation-contraction uncoupling with a silent heart cardiac troponin (tnnt2) morpholino (to eliminate optical mapping motion artifact associated with contraction), $\mathrm{Ca}^{2+}$ transients were measured in vivo at various regions of the zebrafish atrium and ventricle in 2 days post-fertilization (dpf) embryos. In wild-type tnnt 2 morpholino-injected zebrafish, repetitive fluorescent waves representing an increase in cytosolic $\mathrm{Ca}^{2+}$ during systole were visualized, spreading from the atrium through the atrioventricular junction and into the ventricle (Figure 2A). In contrast, in the $k c n h 2^{s 290}$ homozygous mutants, $\mathrm{Ca}^{2+}$ waves were visible in the atrium but not in the ventricle (Figure 2A), implying impaired ventricular $\mathrm{Ca}^{2+}$ cycling.

The above investigation was followed by a study using the same zebrafish line to map $\mathrm{Ca}^{2+}$ waves across the whole heart in intact embryos at various ages to investigate the development of the vertebrate cardiac conduction system (Figure 2B) (Chi et al., 2008). Four distinct stages of conduction development were identified, which corresponded to specific cellular and anatomical changes in the developing heart and were dependent on epigenetic mechanical factors such as hemodynamic flow and contraction. An in vivo optical mapping technique was then used as a phenotypic assay to perform a forward genetic screen, which identified 17 conduction-specific mutations (Figure 2B), thought to represent novel genetic regulators of the cardiac conduction system. A similar approach has been applied to other genes whose mutation is known to affect cardiac conduction, such as the Popeye domain containing $(P o p d c)$ gene family, with morpholino knock down of popdc2 in 5-6 dpf embryos causing sinoatrial node conduction failure, irregular atrial and ventricular activity, and varying degrees of atrioventricular block (Kirchmaier et al., 2012).

More recently, zebrafish have been used to help in the assessment of novel GECIs for cardiac-specific applications, such as those with a ratiometric readout, which is useful for assessing absolute changes in $\mathrm{Ca}^{2+}$ and to help correct for the motion artifact that occurs with optical mapping in the beating heart. Four available ratiometric Förster resonance energy transfer (FRET)-based GECIs with varying $\mathrm{Ca}^{2+}$-binding affinity (TNXXL, Twitch-1, Twitch-2B, and Twitch-4) were transiently expressed in the hearts of zebrafish embryos (driven by the $c m l c 2$ promoter) and kinetic parameters of atrial and ventricular $\mathrm{Ca}^{2+}$ transients were measured at $3 \mathrm{dpf}$ under various conditions. Ultimately, this revealed that Twitch- 1 and Twitch- 4 are the most promising for use in the heart, based on their greater sensitivity, faster kinetics, and higher affinity for $\mathrm{Ca}^{2+}$ (Figure 3) (Salgado-Almario et al., 2020).

\section{Genetically Encoded Voltage Indicators (GEVIs)}

The development of effective GEVIs has been slower than GECIs, owing to difficulties in achieving sufficiently fast kinetics and avoiding electrophysiological interference. Recently, significant progress has been made, which includes their application for cardiac research. The first reported use of GEVIs in the heart was in fact in zebrafish (Tsutsui et al., 2010), which utilized a FRET-based voltage-sensitive fluorescent protein (VSFP) called Mermaid (Tsutsui et al., 2008). The 
TABLE 2 | Previous applications of cardiac optogenetics using zebrafish.

\begin{tabular}{|c|c|c|c|c|}
\hline & Publication & Age of study & Optogenetic line & Application/finding \\
\hline \multirow{7}{*}{ 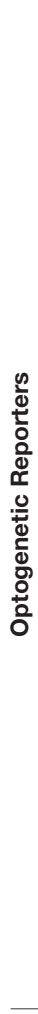 } & Arnaout et al., 2007 & $2 \mathrm{dpf}$ & $\operatorname{Tg}(\mathrm{cm} / c 2: g C a M P)^{s 878}$ & $\begin{array}{l}\text { Investigated mutant model of inherited long QT syndrome, in which loss of rapid } \\
\text { delayed-rectifier potassium current }\left(I_{\mathrm{Kr}}\right) \text { due to } \mathrm{kcnh} 2 \text { mutation results in mechanical } \\
\text { ventricular asystole. Showed lack of calcium }\left(\mathrm{Ca}^{2+}\right) \text { waves in the ventricle, suggesting } \\
\text { impaired } \mathrm{Ca}^{2+} \text { cycling. }\end{array}$ \\
\hline & Chi et al., 2008 & $1-21 \mathrm{dpf}$ & $\operatorname{Tg}(\mathrm{cm} / \mathrm{c} 2: g C a M P)^{s 878}$ & $\begin{array}{l}\text { Investigated development of the vertebrate cardiac conduction system and } \\
\text { performed a forward genetic screen. Identified four stages of conduction } \\
\text { development, which depended on epigenetic mechanical factors, and identified } 17 \\
\text { conduction-specific mutations that may represent novel genetic regulators of the } \\
\text { cardiac conduction system. }\end{array}$ \\
\hline & Tsutsui et al., 2010 & 2-3 dpf & Tg(cm/c2:Mermaid) & $\begin{array}{l}\text { Investigated the effect of the histamine } \mathrm{H} 1 \text { receptor blocker astemizole on cardiac } \\
\text { excitation. Showed that astemizole caused retrograde propagation from the } \\
\text { atrioventricular boundary to the atrium. }\end{array}$ \\
\hline & Kirchmaier et al., 2012 & $5-6 \mathrm{dpf}$ & $\operatorname{Tg}(\mathrm{cm} / \mathrm{c} 2: g C a M P)^{s 878}$ & $\begin{array}{l}\text { Investigated effect of Popeye domain containing gene } 2 \text { knock-down. Caused } \\
\text { sinoatrial node conduction failure, irregular atrial and ventricular activity, and varying } \\
\text { degrees of atrioventricular block. }\end{array}$ \\
\hline & Hou et al., 2014 & $1.5-4 \mathrm{dpf}$ & $\begin{array}{l}\text { Tg(cm/c2:Arch(D95N)- } \\
\text { GCaMP5G) [“CaViar”] }\end{array}$ & $\begin{array}{l}\text { Investigated the effects of L-type } \mathrm{Ca}^{2+}\left(I_{\mathrm{Ca}, \mathrm{L}}\right) \text { or fast sodium current block. Showed } \\
\text { that }<4 \mathrm{dpf} \text {, cardiac excitation is initiated by } \mathrm{Ca}^{2+} \text {, but by } 4 \mathrm{dpf} \text { ventricular excitation } \\
\text { it is initiated by sodium, while atrial excitation remains } \mathrm{Ca}^{2+} \text { dependent. }\end{array}$ \\
\hline & van Opbergen et al., 2018a & $3,14 \mathrm{dpf}$ & $\begin{array}{l}\text { Tg(myl7:chimeric } \\
\text { VSFP-butterfly CY) } \\
\text { Tg(myl7:Gal4FF; } \\
\text { UAS:GCaMP6f) }\end{array}$ & $\begin{array}{l}\text { Investigated effects of pharmacological modulation of the sympathetic nervous } \\
\text { system or ion channels on cardiac electrophysiology and } \mathrm{Ca}^{2+} \text { cycling. Showed that: } \\
\text { (i) sympathetic stimulation or block increased or decreased diastolic } \mathrm{Ca}^{2+} \text { and } \mathrm{Ca}^{2+} \\
\text { transient amplitudes; (ii) } I_{\mathrm{Kr}} \text { block increased action potential duration; (iii) } I_{\mathrm{Ca}, \mathrm{L}} \text { block } \\
\text { prevented } \mathrm{Ca}^{2+} \text { transients, increased ventricular action potential duration, and } \\
\text { disrupted atrioventricular conduction; and (iv) differences exist in atrial and ventricular } \\
\mathrm{Ca}^{2+} \text { cycling during development. }\end{array}$ \\
\hline & Salgado-Almario et al., 2020 & $3 \mathrm{dpf}$ & $\begin{array}{l}\text { Tg(cm/c2:Twitch-1) } \\
\operatorname{Tg}(\mathrm{cm} / \mathrm{c} 2: \text { Twitch-2B) } \\
\operatorname{Tg}(\mathrm{cm} / \mathrm{c} 2: \text { Twitch-4) } \\
\operatorname{Tg}(\mathrm{cm} / \mathrm{c} 2: \operatorname{TN}-X X \mathrm{~L})\end{array}$ & $\begin{array}{l}\text { Tested various novel genetically encoded ratiometric calcium indicators to determine } \\
\text { which are the most promising for use in the heart. }\end{array}$ \\
\hline \multirow{2}{*}{ 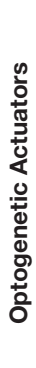 } & Arrenberg et al., 2010 & $1-5 \mathrm{dpf}$ & $\begin{array}{l}\text { Tg(E1b:Gal4- } \\
\text { VP16 } 1101 t ; \\
\text { UAS:NpHR- } \\
\text { mCherrys1989t) } \\
\text { Tg(E1b:Gal4 }{ }^{\text {s1101t; }} \\
\text { UAS:ChR2(H134R)- } \\
\text { eYFPs1990t) }\end{array}$ & $\begin{array}{l}\text { Mapped cardiac pacemaker development. Showed that: (i) at } 1 \mathrm{dpf} \text {, the pacemaker is } \\
\text { at the venous pole; (ii) at } 2 \mathrm{dpf} \text {, it is more confined to the sinoatrial ring; and (iii) by } 3 \\
\mathrm{dpf} \text { it is more defined and confined to the dorsal right quadrant of the sinoatrial ring. } \\
\text { Further, in } 4 \text { dpf embryos, heart rate could be control by pulsed light stimulation of the } \\
\text { sinoatrial ring. }\end{array}$ \\
\hline & Kopton et al., 2018 & $3 \mathrm{mpf}$ & $\begin{array}{l}\operatorname{Tg}(\mathrm{cm} / \mathrm{c} 2: \mathrm{GtACR} 1- \\
\text { eGFP) }\end{array}$ & $\begin{array}{l}\text { Tested whether the heart could be silenced with anion-specific light-activated ion } \\
\text { channel. Showed that stimulation applied during the resting (diastolic) phase of the } \\
\text { action potential causes depolarization and excitation, but causes repolarization and } \\
\text { shortening of the action potential if applied during the (systolic) plateau. }\end{array}$ \\
\hline
\end{tabular}

dpf, days post-fertilization. For further details on the optogenetic zebrafish lines, including the meaning of the abbreviations, see the relevant sections of the text.

Mermaid construct consists of a green-emitting fluorescent donor (mUKG; Umi-Kinoko from Sarcophyton) and an orange-emitting fluorescent acceptor (мКОк; Kusabira from Fungia concinna) fused to a voltage sensing phosphatase from Ciona intestinalis (Ci-VSP) with a transmembrane domain homologous to the S1-S4 segments of voltage-gated potassium (Kv) channels (Murata et al., 2005). The Mermaid reporter was expressed specifically in the zebrafish heart under the $\mathrm{cmcl} 2$ promotor [ $\mathrm{Tg}(\mathrm{cmlc2}: M e r m a i d)]$ and used for in vivo voltage mapping in 2-3 dpf embryos under normal conditions and after application of the histamine H1 receptor blocker astemizole (known to also block $I_{\mathrm{Kr}}$ ). Measurements showed that astemizole disrupted the normal sequence of cardiac excitation, causing retrograde propagation from the atrioventricular boundary to the atrium (Figure 4A) (Tsutsui et al., 2010).

Since that time, a variety of new GEVIs have been developed with improved sensitivity and kinetics. In a recent study using zebrafish (van Opbergen et al., 2018a), the novel GEVI chimeric VSFP-butterfly CY (cyan-yellow, mCitrine/mCerulean) (Mishina et al., 2014) or the updated GECI GCaMP6f (Chen et al., 2013) were expressed in the heart of pigment-deficient, opticallytransparent casper mutant zebrafish (White et al., 2008), with the myosin light chain 7 (myl7) promotor [ $\mathrm{Tg}($ myl7:chimeric VSFPbutterfly $C Y$ ) and $T g$ (myl7:Gal4FF; UAS:GCaMP6f)]. The hearts of $3 \mathrm{dpf}$ and $14 \mathrm{dpf}$ zebrafish were imaged after administration of drugs targeting the sympathetic nervous system or various cardiac ion channels to assess effects on electrical activation, 


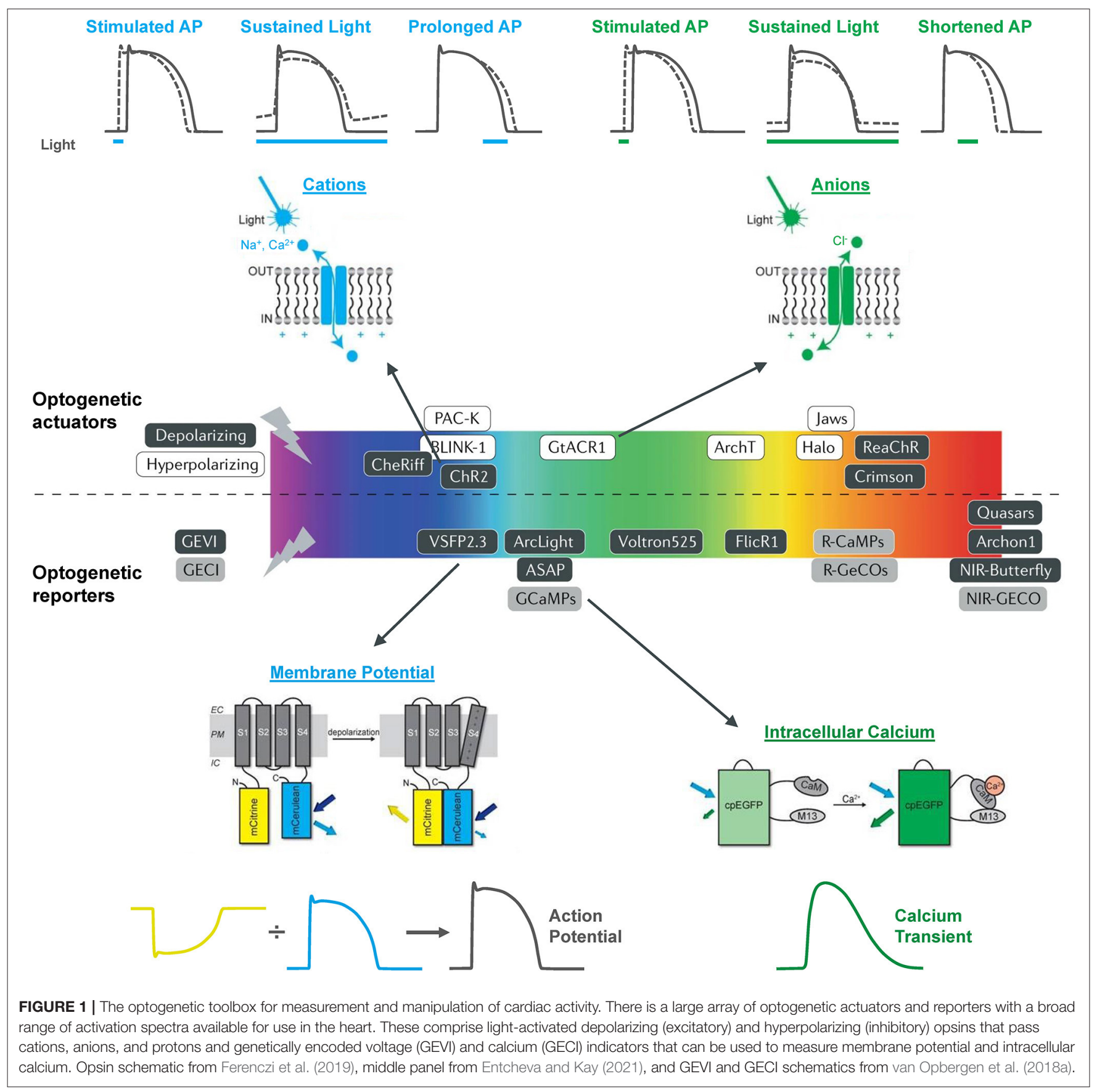

action potential morphology, and intracellular $\mathrm{Ca}^{2+}$ dynamics (van Opbergen et al., 2018a) (Figure 4B). It was shown that: (i) $\beta$ adrenergic receptor stimulation (with isoproterenol) or blockade (with propranolol) increased or decreased diastolic $\mathrm{Ca}^{2+}$ levels and $\mathrm{Ca}^{2+}$ transient amplitudes, respectively; (ii) $I_{\mathrm{Kr}}$ block (with E-4031) increased action potential duration; (iii) L-type calcium current $\left(I_{\mathrm{Ca}, \mathrm{L}}\right)$ block (with nifedipine) prevented $\mathrm{Ca}^{2+}$ transients, increased ventricular action potential duration, and disrupted atrioventricular conduction; and (iv) differences exist in atrial and ventricular $\mathrm{Ca}^{2+}$ recovery dynamics between 3 and $14 \mathrm{dpf}$ zebrafish (but not in the $\mathrm{Ca}^{2+}$ upstroke).

\section{Combined Voltage- $\mathrm{Ca}^{2+}$ Imaging}

Functional fluorescent dyes can be combined for simultaneous mapping of voltage and $\mathrm{Ca}^{2+}$ in the whole heart (Herron et al., 2012). There is similar interest in combining GEVIs and GECIs for dual voltage-Ca ${ }^{2+}$ imaging, however this is generally 

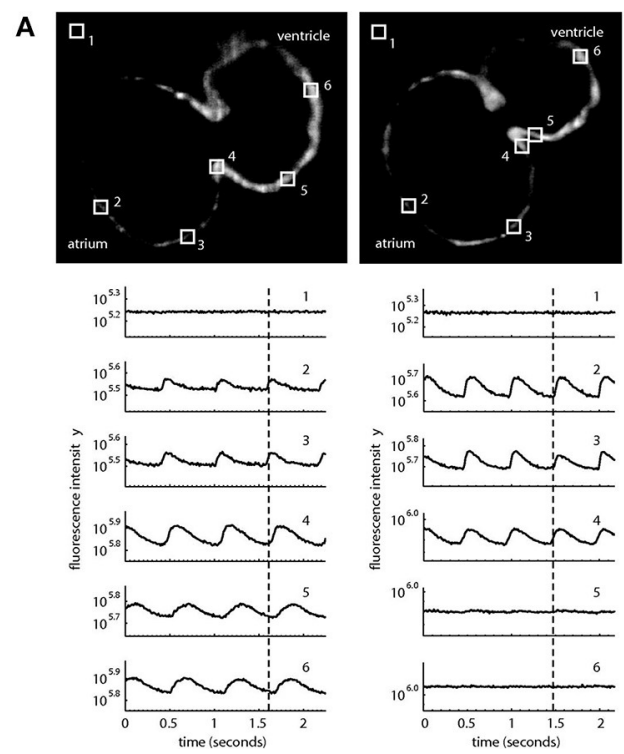
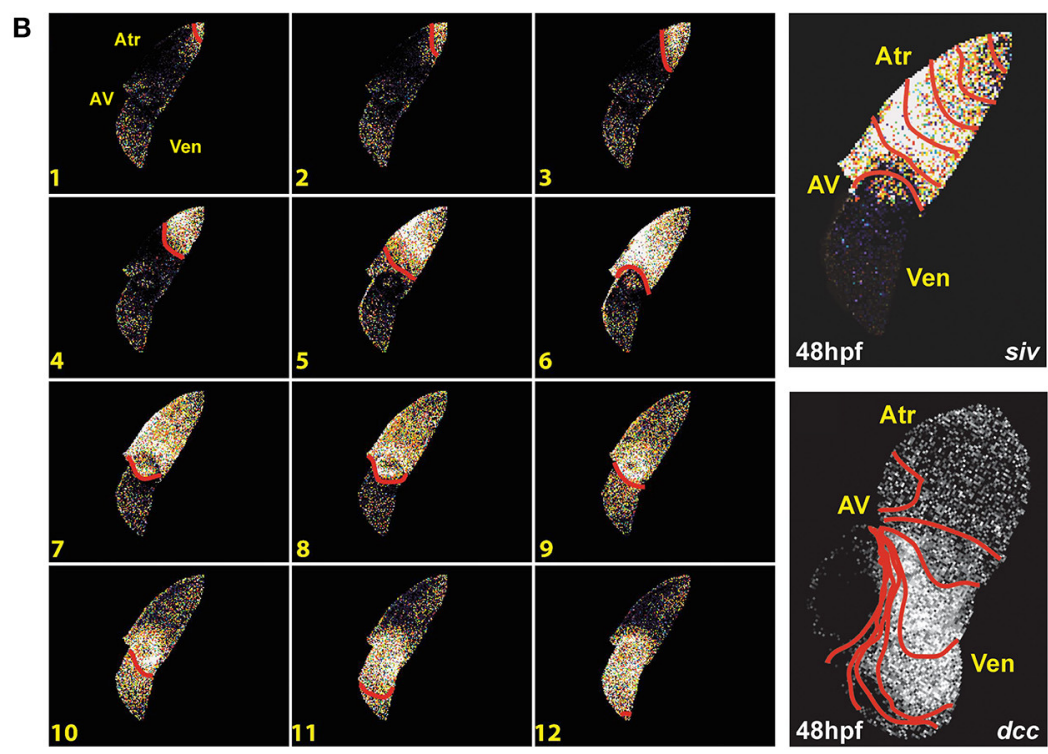

FIGURE 2 | In vivo imaging of intracellular calcium using genetically encoded calcium indicators (GECls) in intact zebrafish embryos. (A) Hearts in $48 \mathrm{~h}$ post-fertilization (hpf) wild-type embryos with cardiac-specific expression of gGCaMP exhibit atrial and ventricular calcium release (left), while hearts in kcnh2s290 mutants exhibit atrial but no ventricular release (right). Each selected region in the images has a corresponding fluorescence signal plotted below. The dotted lines mark an arbitrary point in time to facilitate comparison across the different signals. From Arnaout et al. (2007). (B) In hearts from 48 hpf wild-type embryos, calcium activation travels from the sinus venosus across the atrium (Atr) and ventricle (Ven), with a delay at the atrioventricular (AV) junction (left), while ventricular conduction is absent in silent ventricle (siv) mutants and disorganized in dococ ${ }^{s 215,226}$ (dcc) mutants (right). Isochronal lines represent $60 \mathrm{~ms}$. From Chi et al. (2008).

prevented by spectral overlap of the relevant fluorescent proteins. The first successful study using a GEVI-GECI construct in the heart was performed in the zebrafish, using a genetically encoded dual-function voltage- $\mathrm{Ca}^{2+}$ reporter ("CaViar," created by fusing the GEVI Arch(D95N) with the GECI GCaMP5) under control of the heart-specific cmlc2 promoter [ $\mathrm{Tg}(\mathrm{cmlc2}$ : $\operatorname{Arch}(\mathrm{D} 95 \mathrm{~N})$ GCaMP5G)] (Hou et al., 2014). Hearts of 1.5-4.5 dpf embryos were imaged during application of the $I_{\mathrm{Ca}, \mathrm{L}}$ blocker nifedipine or fast sodium channel blocker quinidine, which showed that early in development the zebrafish cardiac AP is initiated by $\mathrm{Ca}^{2+}$, but by $4 \mathrm{dpf}$ the ventricular AP becomes driven by sodium, while the atrial AP remains $\mathrm{Ca}^{2+}$ dependent (Figure 4C).

\section{STUDIES UTILIZING OPTOGENETIC ACTUATORS IN THE ZEBRAFISH HEART}

Optogenetic actuators are light-activated proteins that generate a transmembrane ion flux. The discovery and cloning of the cation-selective ion channel channelrhodopsin-2 (ChR2) from the green alga Chlamydomonas reinhardtii in 2003 (Nagel et al., 2003) has led to the development of an extensive toolkit that includes depolarizing (excitatory) and hyperpolarizing (inhibitory) opsins, which are activated across a wide spectrum of wavelengths, and may be used for manipulation of cardiac membrane potential (Figure 1) (Schneider-Warme, 2018; Ferenczi et al., 2019; Entcheva and Kay, 2021). As for the cardiac application of GEVIs and GECIs, one of the first reports of the use of optogenetic actuators in the heart was in zebrafish (Arrenberg et al., 2010). This involved the use of both ChR2 [Tg(E1b:Gal4 ${ }^{\text {s1101t }}$; UAS:ChR2(H134R)$\left.\left.e Y F P^{s 1990 t}\right)\right]$ and the chloride-specific ion channel halorhodopsin from Natronomonas pharaonis (NpHR) (Zhang et al., 2007)

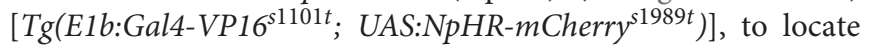
and control cardiac pacemaker cells in intact 1-5 dpf zebrafish embryos. In NpHR-expressing zebrafish, maps were generated at each day post-fertilization by sequentially illuminating small, overlapping regions of the heart, and measuring the heart rate response, or the incidence of cardiac arrest or arrhythmia (Figure 5A). It was found that: (i) at $1 \mathrm{dpf}$, the heart stopped beating when a region at the venous pole was illuminated, indicating the location of the pacemaker; (ii) at $2 \mathrm{dpf}$, the pacemaker region was more confined to the sinoatrial ring, with illumination of large adjacent areas having no effect, and atrioventricular block (of varying degree, depending on light intensity) occurred with illumination of the atrioventricular canal; and (iii) at $3 \mathrm{dpf}$, the pacemaker region was more defined, being confined to the dorsal right quadrant of the sinoatrial ring. It was further found that in $4 \mathrm{dpf}$ embryos, pulsed photo-stimulation of the sinoatrial ring at a frequency of $2.7-4.7 \mathrm{~Hz}$ with $\mathrm{ChR} 2$ was able to control heart rate.

Since the time of that pioneering study, another prominent family of chloride-specific light-activated ion channels has been developed, the Guillardia theta anion channelrhodopsin 1 and 2 (GtACR1 and GtACR2) (Govorunova et al., 2015), which have been shown to silence neuronal AP generation (including in zebrafish) (Malyshev et al., 2017; Mauss et al., 


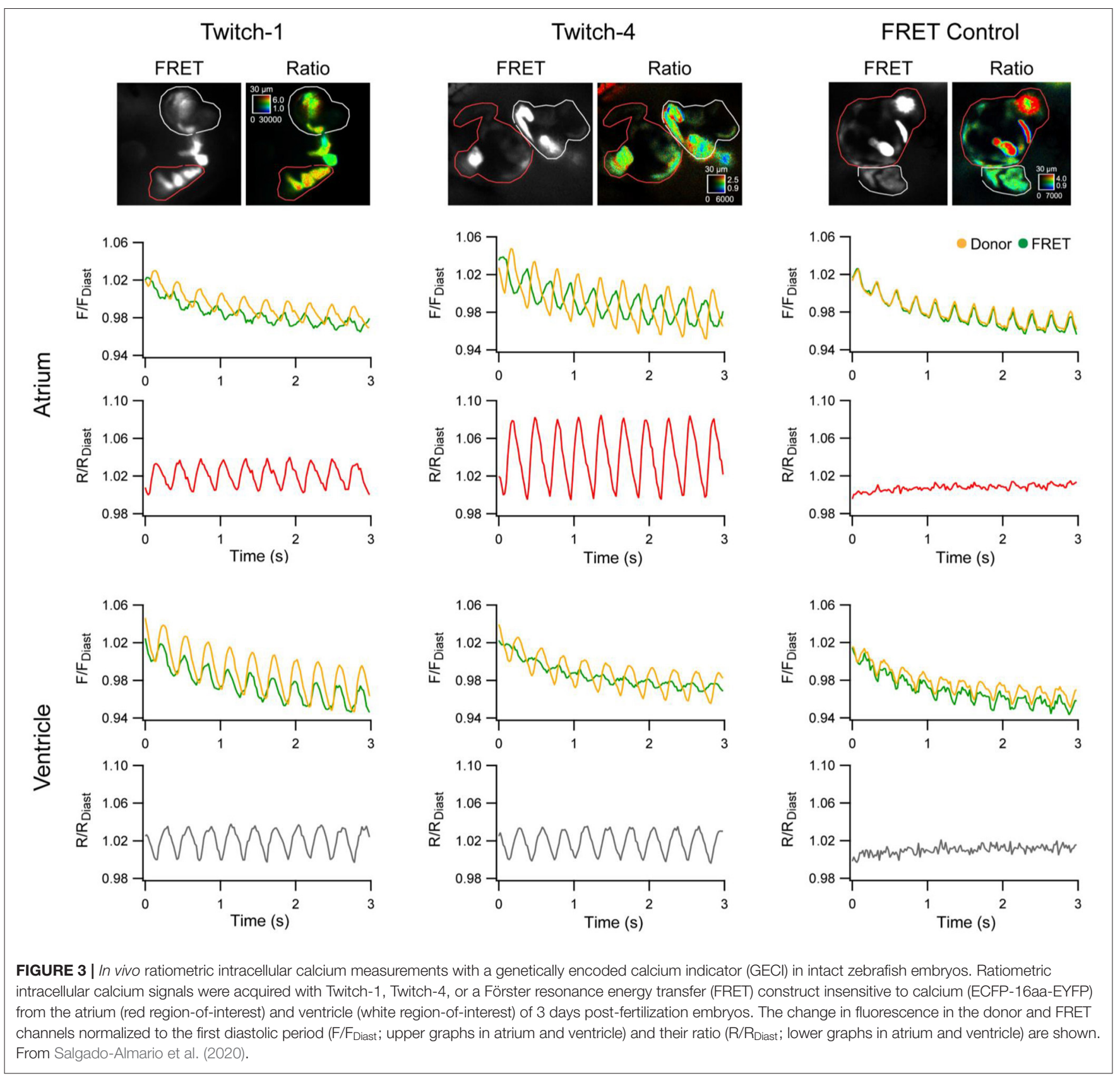

2017; Mohamed et al., 2017; Forli et al., 2018). The first cardiac application of GtACR1 involved zebrafish [using hearts isolated from 3 months post-fertilization adults with cardiacspecific GtACR1 expression, $T g(c m l c 2: G t A C R 1-e G F P)]$, which in combination with experiments in genetically transfected single rabbit ventricular myocytes demonstrated that GtACR1 activation causes depolarization of ventricular myocytes when applied during the resting (diastolic) phase of the AP (and if suprathreshold, results in excitation), but causes repolarization when applied during the (systolic) plateau (resulting in shortening of the AP). This biphasic response relates to the reversal potential of chloride in ventricular myocytes, which is somewhere between -40 and $-33 \mathrm{mV}$ (Clemo et al., 1999), so that the flow of negative ions switches from outward (causing depolarization) to inward (causing repolarization) as cells are excited. As a result, pulsed illumination can be used to pace the heart, while sustained illumination can arrest the heart in a depolarized state (Figure 5B) (Kopton et al., 2018). This indicates that while GtACR1 does not address the need for optogenetic silencing through a physiological means (i.e., hyperpolarization), it is a potentially attractive tool for exciting cardiomyocytes by transient light-induced depolarization. 
A
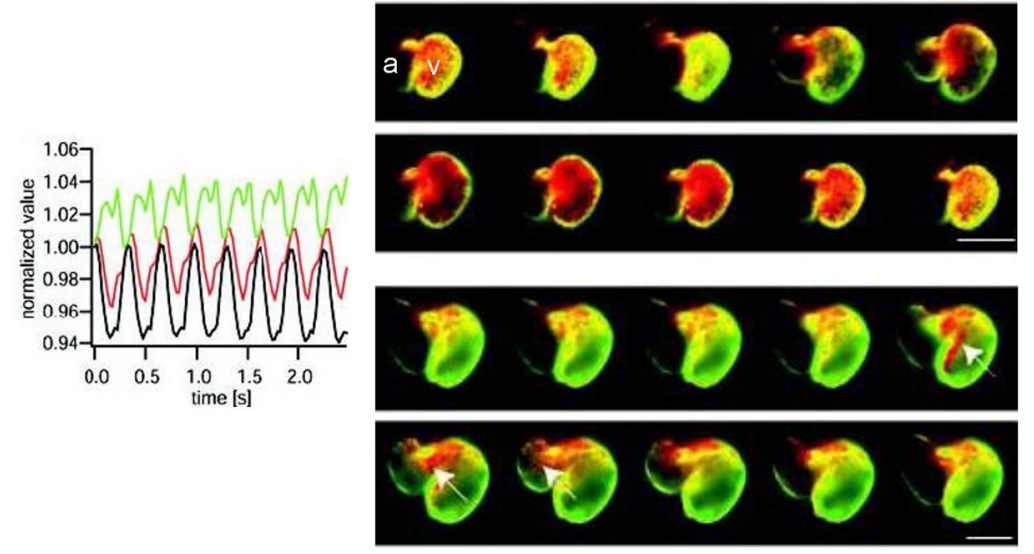

B
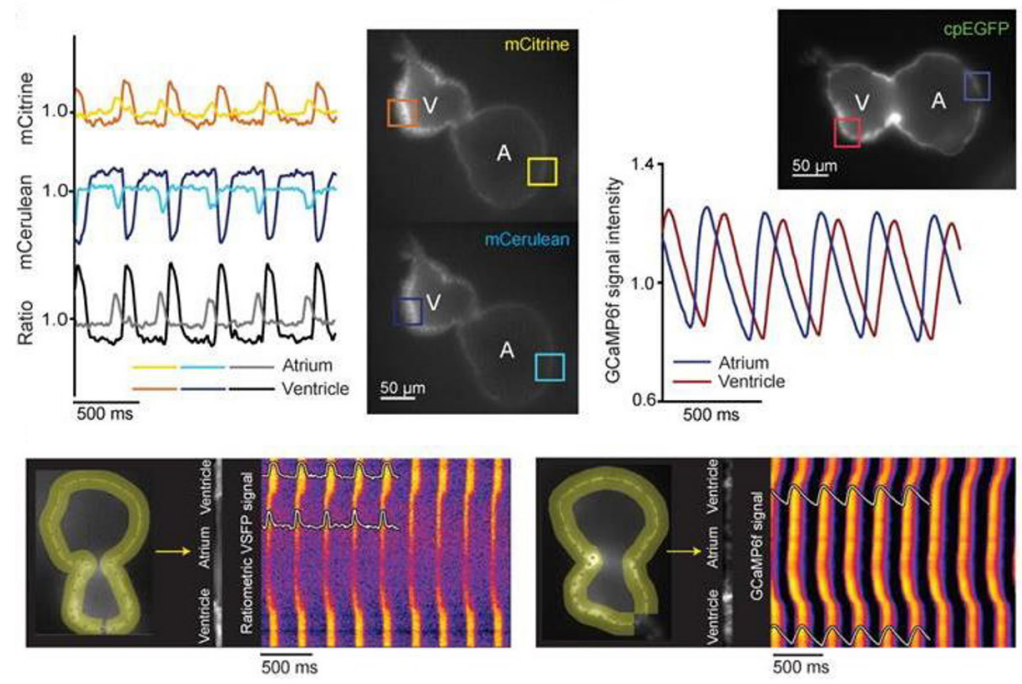

C
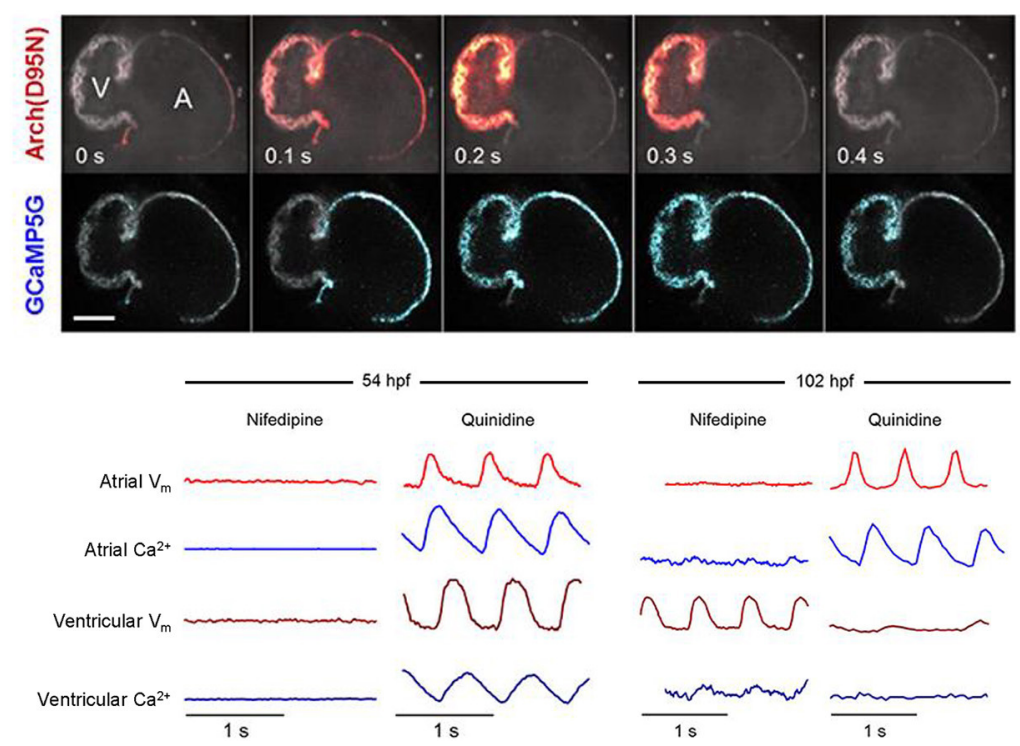

FIGURE 4 | In vivo imaging of membrane potential using genetically encoded voltage indicators (GEVIs), combined with genetically encoded calcium indicators (GECls) in intact zebrafish embryos. (A) Signals (left) from a donor (mUKG, green) and acceptor (mKOK, red) Förster resonance energy transfer (FRET) pair of fluorescent proteins and their ratio ( $\mathrm{mKO} / \mathrm{mUKG}$, black) acquired from the ventricle of a 3 days post-fertilization (dpf) zebrafish embryo with cardiac-specific 
FIGURE 4 | expression of the GEVI Mermaid. Pseudo-colored ratio images (right) representing a single cardiac cycle in wild-type, Mermaid-expressing zebrafish (upper) showing propagation of excitation from the sinus venosus in the atrium (a) to the ventricle (v), and in astemizole-treated (5 $\mu \mathrm{M}, 15 \mathrm{~min})$ zebrafish (lower) showing retrograde propagation from the ventricle to the atrium (highlighted with arrows). Scale bar, $100 \mu \mathrm{m}$. From Tsutsui et al. (2010). (B) Signals (upper left) from a donor (mCerulean, blue) and acceptor (mCitrine, yellow) Förster resonance energy transfer (FRET) pair of fluorescent proteins and their ratio ( $\mathrm{mCitrine/mCerulean,}$ black) acquired from the regions of interest (boxes in fluorescent images) indicated on the atrium (A) and ventricle $(\mathrm{V})$ of a 3 dpf zebrafish embryo with cardiac-specific expression of GEVI VSFP-butterfly CY. Signals (upper right) acquired from the atrium (blue) and ventricle (red) of a 3 dpf zebrafish embryo with cardiac-specific expression of the GECI GCaMP6f. Line plots of chimeric VSFP-butterfly CY (lower left) and GCaMP6f (lower right) background-corrected fluorescence intensities averaged across the width of the myocardial wall superimposed on heat maps of trajectory vs. time illustrating electrical impulse and $\mathrm{Ca}^{2+}$ propagation throughout the heart. cpEGFP, circularly permutated enhanced green fluorescent protein. From van Opbergen et al. (2018a). (C) Single optical sections of a 4 dpf zebrafish heart with cardiac-specific expression of the GEVI-GECl construct CaViar showing GEVI Arch(D95N) (top) and GECI GCaMP5G (middle) fluorescence as excitation propagates from the atrium (A) to ventricle $(\mathrm{V})$. Voltage $\left(\mathrm{V}_{\mathrm{m}}\right.$, red) and calcium $\left(\mathrm{Ca}^{2+}\right.$, blue) signals acquired from the atrium and ventricle of 50 (upper left) and 102 (lower right) hours post-fertilization (hpf) zebrafish embryos exposed to nifedipine (L-type $\mathrm{Ca}^{2+}$ channel blocker) and quinidine (fast sodium channel blocker). At $52 \mathrm{hpf}$, nifedipine reversibly suppressed voltage and $\mathrm{Ca}^{2+}$ dynamics in both chambers, while quinidine had no effect. At $102 \mathrm{hpf}$, nifedipine largely suppressed calcium transients in both chambers but only suppressed atrial voltage, while quinidine largely suppressed voltage and calcium transients in the ventricle but did not affect either transient in the atrium. Scale bar, $50 \mu \mathrm{m}$. From Hou et al. (2014).

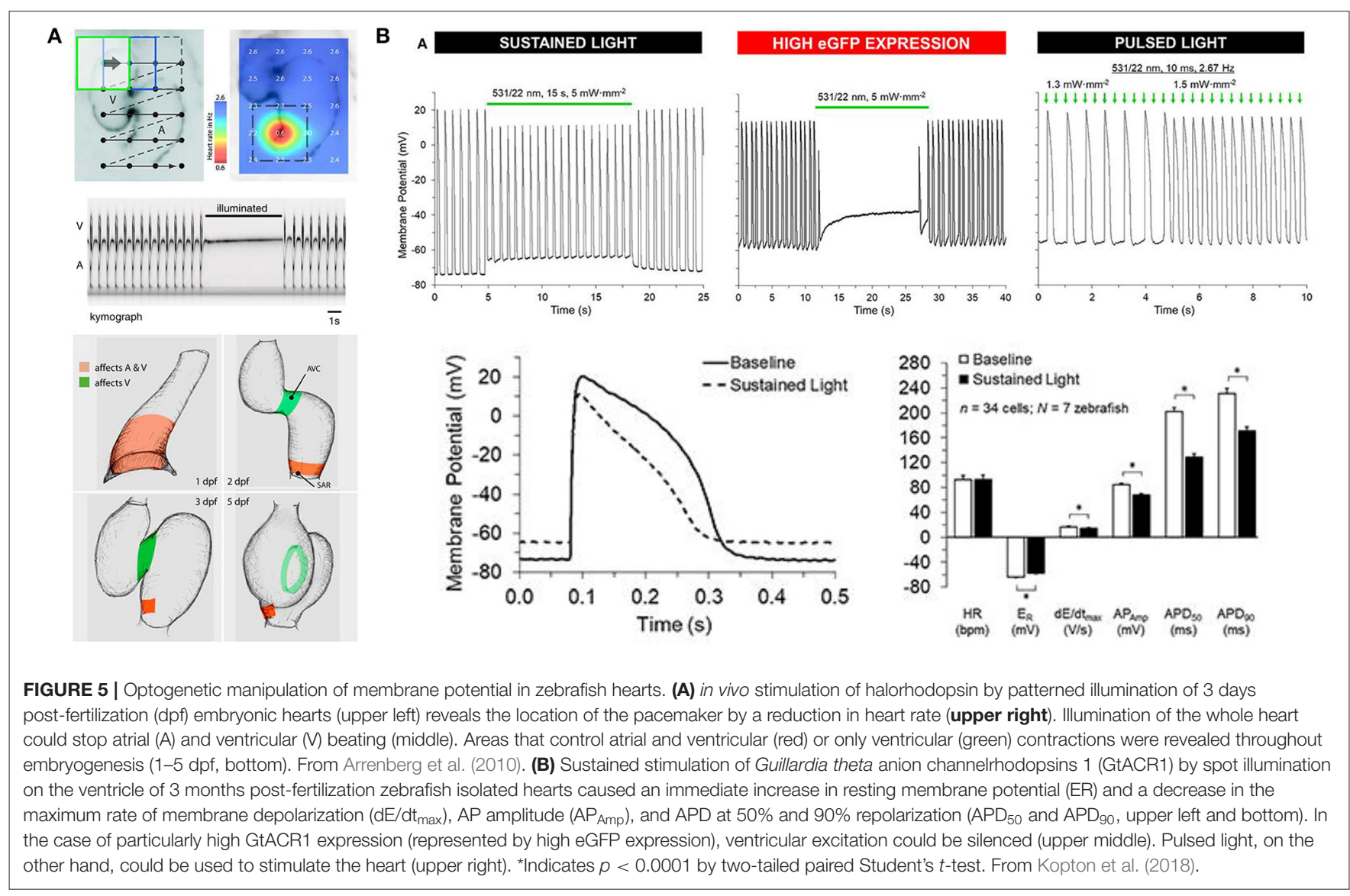

\section{FUTURE DIRECTIONS FOR THE USE OF CARDIAC OPTOGENETICS IN ZEBRAFISH}

Unlike the prevalent use of optogenetics in zebrafish to study the nervous system (Del Bene and Wyart, 2012; Simmich et al., 2012; Portugues et al., 2013), there have been relatively few cardiac optogenetic studies performed in zebrafish (summarized in Table 2), yet those studies have been fundamental in progressing the application of optogenetic technologies to the heart. With the continual improvement of optogenetic techniques (Entcheva and Kay, 2021), the use of zebrafish for integrative (patho-)physiological cardiac structure-function studies holds great promise. Future research will be driven by technological advances such as high-speed, cell-accurate, threedimensional mapping (Mickoleit et al., 2014; Weber et al., 2017; Sacconi et al., in press), more effective methods for cellspecific spatial and temporal gene expression (Reade et al., 2017; LaBelle et al., 2021), and novel optogenetic actuators and reporters with enhanced expression, fluorescence, and kinetics, combined with improved light delivery (Entcheva and Kay, 2021). As the field continues to develop, the zebrafish may be invaluable for cardiac optogenetic studies directly 
related to its strengths as an experimental model (Table 1; i.e., development, genetic screening, drug discovery, cardiotoxicity testing, disease modeling, all-optical studies of electrophysiology and cell signaling, and anti-arrhythmic strategy development). It may also be a powerful tool for fundamental investigations of the hetero-cellular heart (e.g., structure-function interactions of myocytes, fibroblasts, intracardiac neurons, and immune and endothelial cells) and in helping to overcome hindrances related to the clinical translation of optogenetic techniques (e.g., genetic transfection, immune responses, phototoxicity) (Richter and Bruegmann, 2020). This will be enhanced by the large number of currently available transgenic lines, genetic material, and tools (easily found through online resources and central repositories), facilitated by the open zebrafish community willing to share them (Rafferty and Quinn, 2018; Stoyek et al., in press).

While a majority of cardiac optogenetic studies in the zebrafish have been performed in the early stages of development, technological advances in fluorescence imaging approaches and methods for spatially-resolved light stimulation have the promise to enable studies to be performed in the adult isolated whole heart and in vivo. This will be aided by the continuing development of transgenic lines that lack pigment and are thus largely transparent throughout their lifespan (i.e., "casper" [White et al., 2008) and "crystal" (Antinucci and Hindges, 2016)], and can be used as a background on which to express optogenetic reporters and actuators along with mutations of interest.

\section{REFERENCES}

Antinucci, P., and Hindges, R. (2016). A crystal-clear zebrafish for in vivo imaging. Sci. Rep. 6, 1-10. doi: 10.1038/srep29490

Arnaout, R., Ferrer, T., Huisken, J., Spitzer, K., Stainier, D. Y. R., Tristani-Firouzi, M., et al. (2007). Zebrafish model for human long QT syndrome. Proc. Natl. Acad. Sci. U. S. A. 104, 11316-11321. doi: 10.1073/pnas.0702724104

Arrenberg, A. B., Stainier, D. Y. R., Baier, H., and Huisken, J. (2010). Optogenetic control of cardiac function. Science 330, 971-974. doi: 10.1126/science.1195929

Ataka, K., and Pieribone, V. A. (2002). A genetically targetable fluorescent probe of channel gating with rapid kinetics. Biophys. J. 82, 509-516. doi: 10.1016/S0006-3495(02)75415-5

Baird, G. S., Zacharias, D. A., and Tsien, R. Y. (1999). Circular permutation and receptor insertion within green fluorescent proteins. Proc. Natl. Acad. Sci. U. S. A. 96, 11241-11246. doi: 10.1073/pnas.96.20.11241

Berenfeld, O., and Efimov, I. (2019). Optical mapping. Card. Electrophysiol. Clin. 11, 495-510. doi: 10.1016/j.ccep.2019.04.004

Bovo, E., Dvornikov, A. V., Mazurek, S. R., de Tombe, P. P., and Zima, A. V. (2013). Mechanisms of $\mathrm{Ca}^{2+}$ handling in zebrafish ventricular myocytes. Pflügers Arch. 465, 1775-1784. doi: 10.1007/s00424-013-1312-2

Bowley, G., Kugler, E., Wilkinson, R., Lawrie, A., Eeden, F., van, Chico, T. J. A., et al. (in press). Zebrafish as a tractable model of human cardiovascular disease. Br. J. Pharmacol. doi: 10.1111/bph.15473

Boyden, E. S., Zhang, F., Bamberg, E., Nagel, G., and Deisseroth, K. (2005). Millisecond-timescale, genetically targeted optical control of neural activity. Nat. Neurosci. 8, 1263-1268. doi: 10.1038/nn1525

Brette, F., Luxan, G., Cros, C., Dixey, H., Wilson, C., and Shiels, H. A. (2008). Characterization of isolated ventricular myocytes from adult zebrafish (Danio rerio). Biochem. Biophys. Res. Commun. 374, 143-146. doi: 10.1016/j.bbrc.2008.06.109

\section{CONCLUSION}

Optogenetics is a powerful and highly successful (Deisseroth, 2010) set of techniques that has been instrumental in recent developments in neuroscience research (Deisseroth, 2015; Kim et al., 2017), and more recently also for cardiac research (Entcheva and Kay, 2021). Zebrafish provide specific advantages as an experimental model for optogenetic cardiac investigations (Gut et al., 2017; Stoyek and Quinn, 2018), and have been instrumental in its early development, suggesting a bright future for this little fish. With the increasing sophistication of optogenetic methods, the zebrafish represents an experimental model with great potential for cardiac optogenetic studies. Hopefully more cardiac researchers will soon begin to see the light.

\section{AUTHOR CONTRIBUTIONS}

JB wrote the manuscript. MS and TQ revised the manuscript. All authors approved the final version.

\section{FUNDING}

This work was supported by the Natural Sciences and Engineering Research Council of Canada (RGPIN-2016-04879 to TQ), the Heart and Stroke Foundation of Canada (G-18-0022185 to TQ), and the Canadian Institutes of Health Research (MOP 342562 to TQ).

Chen, T.-W., Wardill, T. J., Sun, Y., Pulver, S. R., Renninger, S. L., Baohan, A., et al. (2013). Ultrasensitive fluorescent proteins for imaging neuronal activity. Nature 499, 295-300. doi: 10.1038/nature12354

Chi, N. C., Shaw, R. M., Jungblut, B., Huisken, J., Ferrer, T., Arnaout, R., et al. (2008). Genetic and physiologic dissection of the vertebrate cardiac conduction system. PLoS Biol. 6:e109. doi: 10.1371/journal.pbio.0060109

Clemo, H. F., Stambler, B. S., and Baumgarten, C. M. (1999). Swelling-activated chloride current is persistently activated in ventricular myocytes from dogs with tachycardia-induced congestive heart failure. Circ. Res. 84, 157-165. doi: 10.1161/01.RES.84.2.157

Deisseroth, K. (2010). Optogenetics. Nat. Methods 8, 26-29. doi: $10.1038 /$ nmeth.f.324

Deisseroth, K. (2015). Optogenetics: 10 years of microbial opsins in neuroscience. Nat. Neurosci. 18, 1213-1225. doi: 10.1038/nn.4091

Deisseroth, K., Feng, G., Majewska, A. K., Miesenböck, G., Ting, A., and Schnitzer, M. J. (2006). Next-generation optical technologies for illuminating genetically targeted brain circuits. J. Neurosci. 26, 10380-10386. doi: 10.1523/JNEUROSCI.3863-06. 2006

Del Bene, F., and Wyart, C. (2012). Optogenetics: a new enlightenment age for zebrafish neurobiology. Dev. Neurobiol. 72, 404-414. doi: 10.1002/dneu.20914

Entcheva, E., and Kay, M. W. (2021). Cardiac optogenetics: a decade of enlightenment. Nat. Rev. Cardiol. 18:349. doi: 10.1038/s41569-020-00478-0

Ferenczi, E. A., Tan, X., and Huang, C. L. H. (2019). Principles of optogenetic methods and their application to cardiac experimental systems. Front. Physiol. 10:1096. doi: 10.3389/fphys.2019.01096

Forli, A., Vecchia, D., Binini, N., Succol, F., Bovetti, S., Moretti, C., et al. (2018). Two-photon bidirectional control and imaging of neuronal excitability with high spatial resolution in vivo. Cell Rep. 22, 3087-3098. doi: 10.1016/j.celrep.2018.02.063 
Genge, C. E., Lin, E., Lee, L., Sheng, X., Rayani, K., Gunawan, M., et al. (2016). The zebrafish heart as a model of mammalian cardiac function. Rev. Physiol. Biochem. Pharmacol. 171,99-136. doi: 10.1007/112_2016_5

Govorunova, E. G., Sineshchekov, O. A., Janz, R., Liu, X., and Spudich, J. L. (2015). Natural light-gated anion channels: a family of microbial rhodopsins for advanced optogenetics. Science 349, 647-650. doi: 10.1126/science.aaa7484

Gut, P., Reischauer, S., Stainier, D. Y. R., and Arnaout, R. (2017). Little fish, big data: zebrafish as a model for cardiovascular and metabolic disease. Physiol. Rev. 97, 889-938. doi: 10.1152/physrev.00038.2016

Haustein, M., Hannes, T., Trieschmann, J., Verhaegh, R., Köster, A., Hescheler, J., et al. (2015). Excitation-contraction coupling in zebrafish ventricular myocardium is regulated by trans-sarcolemmal $\mathrm{Ca}^{2+}$ influx and sarcoplasmic reticulum $\mathrm{Ca}^{2+}$ release. PLOS ONE 10:e125654. doi: 10.1371/journal.pone.0125654

Herron, T. J., Lee, P., and Jalife, J. (2012). Optical imaging of voltage and calcium in cardiac cells and tissues. Circ. Res. 110, 609-623. doi: 10.1161/CIRCRESAHA.111.247494

Hou, J. H., Kralj, J. M., Douglass, A. D., Engert, F., and Cohen, A. E. (2014). Simultaneous mapping of membrane voltage and calcium in zebrafish heart in vivo reveals chamber-specific developmental transitions in ionic currents. Front. Physiol. 5:344. doi: 10.3389/fphys.2014.00344

Howe, K., Clark, M. D., Torroja, C. F., Torrance, J., Berthelot, C., Muffato, M., et al. (2013). The zebrafish reference genome sequence and its relationship to the human genome. Nature 496, 498-503. doi: 10.1038/nature12111

Hu, N., Yost, H. J., and Clark, E. B. (2001). Cardiac morphology and blood pressure in the adult zebrafish. Anat. Rec. 264, 1-12. doi: 10.1002/ar.1111

Ishibashi, S., Kroll, K. L., and Amaya, E. (2008). A method for generating transgenic frog embryos. Methods Mol. Biol. 461, 447-466. doi: 10.1007/978-1-60327-483-8_31

Jaimes, R. III, Walton, R. D., Pasdois, P., Bernus, O., Efimov, I. R., et al. (2016). Arrhythmias, electrophysiology, and optical mapping: a technical review of optical mapping of intracellular calcium within myocardial tissue. Am. J. Physiol. Heart Circ. Physiol. 310, H1388-H401. doi: 10.1152/ajpheart.00665.2015

Kaestner, L., Scholz, A., Tian, Q., Ruppenthal, S., Tabellion, W., Wiesen, K., et al. (2014). Genetically encoded $\mathrm{Ca}^{2+}$ indicators in cardiac myocytes. Circ. Res. 114, 1623-1639. doi: 10.1161/CIRCRESAHA.114.303475

Kaestner, L., Tian, Q., Kaiser, E., Xian, W., Müller, A., Oberhofer, M., et al. (2015). Genetically encoded voltage indicators in circulation research. Int. J. Mol. Sci. 16, 21626-21642. doi: 10.3390/ijms160921626

Kim, C. K., Adhikari, A., and Deisseroth, K. (2017). Integration of optogenetics with complementary methodologies in systems neuroscience. Nat. Rev. Neurosci. 18, 222-235. doi: 10.1038/nrn.2017.15

Kirchmaier, B. C., Poon, K. L., Schwerte, T., Huisken, J., Winkler, C., Jungblut, B., et al. (2012). The Popeye domain containing 2 (popdc2) gene in zebrafish is required for heart and skeletal muscle development. Dev. Biol. 363, 438-450. doi: 10.1016/j.ydbio.2012.01.015

Kithcart, A. P., and MacRae, C. A. (2018). Zebrafish assay development for cardiovascular disease mechanism and drug discovery. Prog. Biophys. Mol. Biol. 138, 126-131. doi: 10.1016/j.pbiomolbio.2018.07.002

Koopman, C. D., Zimmermann, W. H., Knöpfel, T., and de Boer, T. P. (2017). Cardiac optogenetics: using light to monitor cardiac physiology. Basic Res. Cardiol. 112, 1-13. doi: 10.1007/s00395-017-0645-y

Kopton, R. A., Baillie, J. S., Rafferty, S. A., Moss, R., Zgierski-Johnston, C. M., Prykhozhij, S. V., et al. (2018). Cardiac electrophysiological effects of light-activated chloride channels. Front. Physiol. 9:1806. doi: 10.3389/fphys.2018.01806

LaBelle, J., Ramos-Martinez, A., Shen, K., Motta-Mena, L. B., Gardner, K. H., Materna, S. C., et al. (2021). TAEL 2.0: an improved optogenetic expression system for zebrafish. Zebrafish 20-28. doi: 10.1089/zeb.2020.1951

Li, X., Gutierrez, D. V., Hanson, M. G., Han, J., Mark, M. D., Chiel, H., et al. (2005). Fast noninvasive activation and inhibition of neural and network activity by vertebrate rhodopsin and green algae channelrhodopsin. Proc. Natl. Acad. Sci. U. S. A. 102, 17816-17821. doi: 10.1073/pnas.0509030102

Lin, E., Shafaattalab, S., Gill, J., Al-Zeer, B., Craig, C., Lamothe, M., et al. (2020). Physiological phenotyping of the adult zebrafish heart. Mar. Genomics 49:100701. doi: 10.1016/j.margen.2019.100701
Llach, A., Molina, C. E., Alvarez-Lacalle, E., Tort, L., Benítez, R., and HoveMadsen, L. (2011). Detection, properties, and frequency of local calcium release from the sarcoplasmic reticulum in teleost cardiomyocytes. PLoS ONE 6:e23708. doi: 10.1371/journal.pone.0023708

MacDonald, E. A., Stoyek, M. R., Rose, R. A., and Quinn, T. A. (2017) Intrinsic regulation of sinoatrial node function and the zebrafish as a model of stretch effects on pacemaking. Prog. Biophys. Mol. Biol. 130, 198-211. doi: 10.1016/j.pbiomolbio.2017.07.012

Malyshev, A. Y., Roshchin, M. V., Smirnova, G. R., Dolgikh, D. A., Balaban, P. M., and Ostrovsky, M. A. (2017). Chloride conducting light activated channel GtACR2 can produce both cessation of firing and generation of action potentials in cortical neurons in response to light. Neurosci. Lett. 640, 76-80. doi: 10.1016/j.neulet.2017.01.026

Mauss, A. S., Busch, C., and Borst, A. (2017). Optogenetic neuronal silencing in drosophila during visual processing. Sci. Rep. 7, 1-12. doi: 10.1038/s41598-017-14076-7

Mickoleit, M., Schmid, B., Weber, M., Fahrbach, F. O., Hombach, S., Reischauer, S., et al. (2014). High-resolution reconstruction of the beating zebrafish heart. Nat. Methods 11, 919-922. doi: 10.1038/nmeth.3037

Miesenböck, G. (2009). The optogenetic catechism. Science 326, 395-399. doi: $10.1126 /$ science.1174520

Mishina, Y., Mutoh, H., Song, C., and Knöpfel, T. (2014). Exploration of genetically encoded voltage indicators based on a chimeric voltage sensing domain. Front. Mol. Neurosci. 7:78. doi: 10.3389/fnmol.2014.00078

Miyawaki, A., Griesbeck, O., Heim, R., and Tsien, R. Y. (1999). Dynamic and quantitative $\mathrm{Ca}^{2+}$ measurements using improved cameleons. Proc. Natl. Acad. Sci. U. S. A. 96, 2135-2140. doi.org/10.1073/pnas.96.5.2135 doi: 10.1073/pnas.96.5.2135

Miyawaki, A., Llopis, J., Heim, R., Michael McCaffery, J., Adams, J. A., Ikura, M., et al. (1997). Fluorescent indicators for $\mathrm{Ca}^{2+}$ based on green fluorescent proteins and calmodulin. Nature 388, 882-887. doi: 10.1038/42264

Mohamed, G. A., Cheng, R.-K., Ho, J., Krishnan, S., Mohammad, F., ClaridgeChang, A., et al. (2017). Optical inhibition of larval zebrafish behaviour with anion channelrhodopsins. BMC Biol. 15:103. doi: 10.1186/s12915-017-0430-2

Morad, M., and Salama, G. (1979). Optical probes of membrane potential in heart muscle. J. Physiol. 292, 267-295. doi: 10.1113/jphysiol.1979.sp012850

Murata, Y., Iwasaki, H., Sasaki, M., Inaba, K., and Okamura, Y. (2005). Phosphoinositide phosphatase activity coupled to an intrinsic voltage sensor. Nature 435, 1239-1243. doi: 10.1038/nature03650

Nagel, G., Brauner, M., Liewald, J. F., Adeishvili, N., Bamberg, E., and Gottschalk, A. (2005). Light activation of channelrhodopsin-2 in excitable cells of Caenorhabditis elegans triggers rapid behavioral responses. Curr. Biol. 15, 2279-2284. doi: 10.1016/j.cub.2005.11.032

Nagel, G., Ollig, D., Fuhrmann, M., Kateriya, S., Musti, A. M., Bamberg, E., et al. (2002). Channelrhodopsin-1: a light-gated proton channel in green algae. Science 296, 2395-2398. doi: 10.1126/science.1072068

Nagel, G., Szellas, T., Huhn, W., Kateriya, S., Adeishvili, N., Berthold, P., et al. (2003). Channelrhodopsin-2, a directly light-gated cation-selective membrane channel. Proc. Natl. Acad. Sci. U. S. A. 100, 13940-13945. doi: 10.1073/pnas. 1936192100

Nemtsas, P., Wettwer, E., Christ, T., Weidinger, G., and Ravens, U. (2010). Adult zebrafish heart as a model for human heart? An electrophysiological study. J. Mol. Cell. Cardiol. 48, 161-171. doi: 10.1016/j.yjmcc.2009.08.034

Portugues, R., Severi, K. E., Wyart, C., and Ahrens, M. B. (2013). Optogenetics in a transparent animal: circuit function in the larval zebrafish. Curr. Opin. Neurobiol. 23, 119-126. doi: 10.1016/j.conb.2012.11.001

Rafferty, S. A., and Quinn, T. A. (2018). A beginner's guide to understanding and implementing the genetic modification of zebrafish. Prog. Biophys. Mol. Biol. 138, 3-19. doi: 10.1016/j.pbiomolbio.2018.0 7.005

Ravens, U. (2018). Ionic basis of cardiac electrophysiology in zebrafish compared to human hearts. Prog. Biophys. Mol. Biol. 138, 38-44. doi: 10.1016/j.pbiomolbio.2018.06.008

Reade, A., Motta-Mena, L. B., Gardner, K. H., Stainier, D. Y., Weiner, O. D., and Woo, S. (2017). TAEL: a zebrafish-optimized optogenetic gene expression system with fine spatial and temporal control. Development 144, 345-355. doi: $10.1242 /$ dev. 139238 
Richter, C., and Bruegmann, T. (2020). No light without the dark: perspectives and hindrances for translation of cardiac optogenetics. Prog. Biophys. Mol. Biol. 154, 39-50. doi: 10.1016/j.pbiomolbio.2019.08.013

Roell, W., Lewalter, T., Sasse, P., Tallini, Y. N., Choi, B.-R., Breitbach, M., et al. (2007). Engraftment of connexin 43-expressing cells prevents post-infarct arrhythmia. Nature 450, 819-824. doi: 10.1038/nature06321

Rotstein, B., and Paululat, A. (2016). On the morphology of the Drosophila heart. J. Cardiovasc. Dev. Dis. 3:15. doi: 10.3390/jcdd3020015

Sabeh, M. K., Kekhia, H., and MacRae, C. A. (2012). Optical mapping in the developing zebrafish heart. Pediatr. Cardiol. 33, 916-922. doi: 10.1007/s00246-012-0300-1

Sacconi, L., Silvestri, L., Rodríguez, E., Armstrong, G. A. B., Pavone, F., Shrier, A., et al. (in press). KHz-rate volumetric voltage imaging of the whole zebrafish heart. Cell Rep. doi: 10.2139/ssrn.3783403

Sakai, R., Repunte-Canonigo, V., Raj, C. D., and Knöpfel, T. (2001). Design and characterization of a DNA-encoded, voltage-sensitive fluorescent protein. Eur. J. Neurosci. 13, 2314-2318. doi: 10.1046/j.0953-816x.2001.01617.x

Salama, G., and Morad, M. (1976). Merocyanine 540 as an optical probe of transmembrane electrical activity in the heart. Science 191, 485-487. doi: 10.1126/science.191.4226.485

Salgado-Almario, J., Vicente, M., Vincent, P., Domingo, B., and Llopis, J. (2020). Mapping calcium dynamics in the heart of zebrafish embryos with ratiometric genetically encoded calcium indicators. Int. J. Mol. Sci. 21:6610. doi: $10.3390 /$ ijms 21186610

Schneider-Warme, F. (2018). The power of optogenetics. Herzschrittmacherther. Elektrophysiol. 29, 24-29. doi: 10.1007/s00399-017-0545-8

Siegel, M. S., and Isacoff, E. Y. (1997). A genetically encoded optical probe of membrane voltage. Neuron 19, 735-741. doi: 10.1016/S0896-6273(00)80955-1

Simmich, J., Staykov, E., and Scott, E. (2012). Zebrafish as an appealing model for optogenetic studies. Prog. Brain Res. 196, 145-162. doi: 10.1016/B978-0-444-59426-6.00008-2

Stoyek, M. R., and Quinn, T. A. (2018). One fish, two fish, red fish, blue fish*: zebrafish as a model for cardiac research. Prog. Biophys. Mol. Biol. 138, 1-2. doi: 10.1016/j.pbiomolbio.2018.11.003

Stoyek, M. R., Quinn, T. A., Croll, R. P., and Smith, F. M. (2016). Zebrafish heart as a model to study the integrative autonomic control of pacemaker function. Am. J. Physiol. Heart Circ. Physiol. 311, H676-H688. doi: 10.1152/ajpheart.00330.2016

Stoyek, M. R., Rafferty, S. A., and Quinn, T. A. (in press). "Genetically modified zebrafish as experimental model," in Handbook of Molecular Biotechnology, ed D. Liu (Boca Raton, FL: CRC Press).

Stoyek, M. R., Rog-Zielinska, E. A., and Quinn, T. A. (2018). Age-associated changes in electrical function of the zebrafish heart. Prog. Biophys. Mol. Biol. 138, 91-104. doi: 10.1016/j.pbiomolbio.2018.07.014

Tallini, Y. N., Ohkura, M., Choi, B.-R., Ji, G., Imoto, K., Doran, R., et al. (2006). Imaging cellular signals in the heart in vivo: cardiac expression of the highsignal $\mathrm{Ca}^{2+}$ indicator GCaMP2. Proc. Natl. Acad. Sci. U. S. A. 103, 4753-4758. doi: $10.1073 /$ pnas.0509378103

Tsutsui, H., Higashijima, S., Miyawaki, A., and Okamura, Y. (2010). Visualizing voltage dynamics in zebrafish heart. J. Physiol. 588, 2017-2021. doi: $10.1113 /$ jphysiol.2010.189126
Tsutsui, H., Karasawa, S., Okamura, Y., and Miyawaki, A. (2008). Improving membrane voltage measurements using FRET with new fluorescent proteins. Nat. Methods 5, 683-685. doi: 10.1038/nmeth.1235

van Opbergen, C. J. M., Koopman, C. D., Kok, B. J. M., Knöpfel, T., Renninger, S. L., Orger, M. B., et al. (2018a). Optogenetic sensors in the zebrafish heart: a novel in vivo electrophysiological tool to study cardiac arrhythmogenesis. Theranostics 8, 4750-4764. doi: 10.7150/thno.26108

van Opbergen, C. J. M., van der Voorn, S. M., Vos, M. A., de Boer, T. P., and van Veen, T. A. B. (2018b). Cardiac $\mathrm{Ca}^{2+}$ signalling in zebrafish: translation of findings to man. Prog. Biophys. Mol. Biol. 138, 45-58. doi: 10.1016/j.pbiomolbio.2018.05.002

Vornanen, M., and Hassinen, M. (2016). Zebrafish heart as a model for human cardiac electrophysiology. Channels 10, 101-110. doi: 10.1080/19336950.2015.1121335

Warkman, A. S., and Krieg, P. A. (2007). Xenopus as a model system for vertebrate heart development. Semin. Cell Dev. Biol. 18, 46-53. doi: 10.1016/j.semcdb.2006.11.010

Weber, M., Scherf, N., Meyer, A. M., Panáková, D., Kohl, P., and Huisken, J. (2017). Cell-accurate optical mapping across the entire developing heart. Elife 6:e28307. doi: 10.7554/eLife.28307.025

White, R. M., Sessa, A., Burke, C., Bowman, T., LeBlanc, J., Ceol, C., et al. (2008). Transparent adult zebrafish as a tool for in vivo transplantation analysis. Cell Stem Cell 2, 183-189. doi: 10.1016/j.stem.2007.11.002

Wolf, M. J., Amrein, H., Izatt, J. A., Choma, M. A., Reedy, M. C., and Rockman, H. A. (2006). Drosophila as a model for the identification of genes causing adult human heart disease. Proc. Natl. Acad. Sci. U. S. A. 103, 1394-1399. doi: 10.1073/pnas.0507359103

Zhang, F., Wang, L.-P., Brauner, M., Liewald, J. F., Kay, K., Watzke, N., et al. (2007). Multimodal fast optical interrogation of neural circuitry. Nature 446, 633-639. doi: $10.1038 /$ nature 05744

Zhang, P.-C., Llach, A., Sheng, X. Y., Hove-Madsen, L., and Tibbits, G. F. (2011). Calcium handling in zebrafish ventricular myocytes. Am. J. Physiol. Regul. Integr. Comp. Physiol. 300, 56-66. doi: 10.1152/ajpregu.00377.2010

Conflict of Interest: The authors declare that the research was conducted in the absence of any commercial or financial relationships that could be construed as a potential conflict of interest.

Publisher's Note: All claims expressed in this article are solely those of the authors and do not necessarily represent those of their affiliated organizations, or those of the publisher, the editors and the reviewers. Any product that may be evaluated in this article, or claim that may be made by its manufacturer, is not guaranteed or endorsed by the publisher.

Copyright (C) 2021 Baillie, Stoyek and Quinn. This is an open-access article distributed under the terms of the Creative Commons Attribution License (CC BY). The use, distribution or reproduction in other forums is permitted, provided the original author(s) and the copyright owner(s) are credited and that the original publication in this journal is cited, in accordance with accepted academic practice. No use, distribution or reproduction is permitted which does not comply with these terms. 